This paper was presented at the Vehicle Noise Regulation and Reduction Session of the Society of Automotive Engineers' Congress and Exposition, Detroit, February 1980, and is reproduced here by permission of the Society.

\title{
Noise Exposure of Truck Drivers
}

\author{
Zygmunt F. Reif and Thomas N. Moore \\ Dept. of Mechanical Engrg. \\ Univ. of Windsor \\ (Windsor/Ontario) \\ Arthur E. Steevensz \\ Pratt and Whitney of Canada, Ltd \\ (Longueuil/Quebec)
}

THIS PAPER PROVIDES DETAILS of a study undertaken to determine the magnitude of the noise exposure of truck drivers running heavy vehicles under commercial operating conditions. Since a number of standard procedures have been developed for in-cab noise measurements, the relationship between these measurements and the noise exposure of the driver has been investigated. Also, an effort was made to identify and quantify various noise sources which contribute to the drivers' exposure during normal operations.

The evaluation of the driver's noise exposure from in-cab noise measurements with standard procedures does not take into account variations in vehicle operation, tire and aerodynamic noise. Additional errors are introduced by placing the microphone at some prescribed distance from the ear, since in that region the sound field can vary significantly. These errors are only partially reduced by the use of noise dose meters.

In this investigation a specially developed, continuously recording instrument is used for measuring the noise exposure of drivers. It is equipped with a sub-miniature microphone which can be easily placed in the cavum of the concha. In previous studies it was shown that the measurement of the sound pressure level at this point was least influenced by extraneous effects.

\section{GENERAL CONSIDERATIONS}

The evaluation of exposure from noise measurements requires integration with respect to time and in accordance with the relationship defined by a particular hearing conservation criterion or regulation. If the noise level is relatively constant, the exposure can be evaluated by approximate integration using sound level meter measurements.

In most applications, however, owing to variations of noise level and movement of the subject, continuous measurement, integration and updating storage are required. Those functions are effectively performed by noise dose meters and several models are now commercially available. The information provided by these instruments is generally restricted only to the numerical
The noise exposure of truck drivers was measured during normal commercial payload runs with special instruments, which are equipped with subminiature microphones. These can be mounted within the cavum of the concha, where measurements are least affected by extraneous effects.

By means of these instruments sound levels were continuously recorded within both ears of the driver and at the centre of the cab. Analysis of results shows that the driver's exposure is highest during freeway hauls and that permanent hearing loss hazard may exist. Frequent use of radio or $C B$ radio can significantly increase this hazard. It is also evident that the sound levels measured within the ears of the driver are generally significantly higher than at the centre of the cab. 
value of the noise dose relative to a particular noise regulation or criterion.

Under certain measuring conditions significant errors may arise due to the location of the microphone on the subject's body. When used in industrial situations, in broadband and diffuse sound fields, these errors are generally relatively small and have a negligible effect on the exposure measurement $(1)$ *

In the presence of dominant discrete frequency components large measuring errors can result from body reflections and shielding. Under these conditions the location of the microphone on the body, the relative positions of the noise sources and their spectral content have significant influence $(2,3)$. Even placing the microphone near the ear does not offer an acceptable improvement. The use of appropriate transfer functions for eliminating the undesirable extraneous influences is, in addition to being very laborious, almost impossible in practice owing to difficulties in determining some of the governing variables. The simplest and most effective solution is to select a measuring location at which the influence of these factors becomes negligibly small. Brammer and Piercy (4) have shown that the cavum of the concha is such a location. This reading can also be relatively easily converted to the sound level at the ear drum, since the corresponding transfer function is independent of the extraneous variables.

The sound field within the truck cab is complex. The main contributors are engine, exhaust, intake, fan, aerodynamic, tire and road noise. The noise transmission is partly airborne and partly structure borne and it is influenced by the construction and shape of the cab. The sound field itself is dominated by discrete frequency components. Spatial variations of the sound level will thus exist in the cab and will change with operating conditions. Results obtained in a previous investigation (5) display the nonuniform and unpredictable distribution of noise levels in truck cabs. Since it is practically impossible to predict or control such variations, the ideal solution is to select a microphone location for exposure measurements at which the influence of these variables is smallest. The cavum of the concha satisfies this requirement. Therefore the basic operator ex-

* Numbers in parentheses designate References at end of paper posure and cab noise measurements were made using the "Ear Bug" unit. This instrument, which was originally developed by the Acoustics Section, Division of Physics, National Research Council of Canada, consists of a subminiature microphone coupled to a modified commercial cassette tape recorder. The system is small and light and can be carried without impediment of normal activities. The microphone can be attached anywhere on the subject and, what is perhaps more important, it is sufficiently small to be placed in the cavum of the concha. A complete temporal record of the A-weighted sound level at the microphone position is available from the cassette tape and can be further analyzed to provide any required information.

\section{PROCEDURE}

A1 158 tested vehicles were supplied by commercial fleet operators. Measurements were performed during normal long distance payload runs. For economic reasons the choice of vehicles, routes and operating conditions was restricted to routine avail. ability. The type of road over which the vehicle travelled was considered to be the operating variable of greatest significance. Each test run was selected to be predominantly of one type i.e. city, highway or freeway. In cases of combined trips, recordings for each road type were analyzed separately.

The driver was always accompanied by a technician who continuously logged operating and weather conditions and monitored instrumentation. Calibration procedures were carried out on relevant instrumentation and calibration signals were recorded on all magnetic tapes.

For the initial series of tests the noise exposure of the driver was recorded only at his right ear. The microphone was placed within the cavum of the concha near the entrance to the ear canal. To obtain worst noise conditions the window on the driver's side was fully opened. It was expected that noise levels at the left ear, which was nearer to the open window, would be higher. However, owing to the possibility of wind induced turbulence at the microphone, this measuring station was not used initially for continuous recording, but only for trial measurements. Evaluation of these results, in particular the narrow band frequency analyses, showed that the turbulence effect was negligible in comparison with other contributing sources and did not influence the noise exposure 
measurements. Consequently, after Vehicle \#17, the exposure of the driver was monitored at both ears. In addition to the measurements made at both ears of the driver, an "Ear Bug" microphone was suspended from the cab ceiling to a position $150 \mathrm{~mm}$ to the right of the driver's ear and at the same level with it. This will be referred to as the centre of cab position.

To obtain a measurement of the basic noise making capacity of each vehicle, in-cab noise measurements were performed in accordance with standard measuring procedures SAE J336a and CSA 2107.23 . The first procedure was significantly longer than the second and required a special test site, which was not readily available for routine testing. The results obtained by both methods were very close and since for the purpose of this study CSA Z107.23 was more acceptable, the use of SAE J336a was eventually discontinued. Measurements for both procedures were taken directly with a precision sound level meter.

\section{DISCUSSION AND RESULTS}

The specifications of the 58 heavy trucks tested are shown in Table 1 . It should be noted that, since the fleet vehicles provided for test runs were, on the average, relatively new and well maintained, the results must therefore be expected to be marginally weighted in favour of lower noise exposures. The Leq values obtained for each vehicle and the corresponding CSA Z107. 23 value are summarized in Table 2 . During some of the test runs, owing to low temperatures, it was found necessary to either close the driver's window partially or close it completely and open the vent window. Measurements taken under these conditions are appropriately marked in this table. In addition, all test runs noted in this table were made with radios off and conversation within the cab reduced as far as possible.

Narrow band frequency spectra were obtained at the three measuring stations (left ear, right ear and centre of cab) during city, highway and freeway driving. Figure 1 shows typical results of such an analysis of the noise recorded at the right ear of a driver during a highway run. It is quite evident that the noise is dominated by discrete frequency components. This was found to be the case at all three measuring stations within the $c a b$ and for each driving condition. Also a progressive reduction of the overall sound level from the left ear to the
Table 1 - Truck Specifications

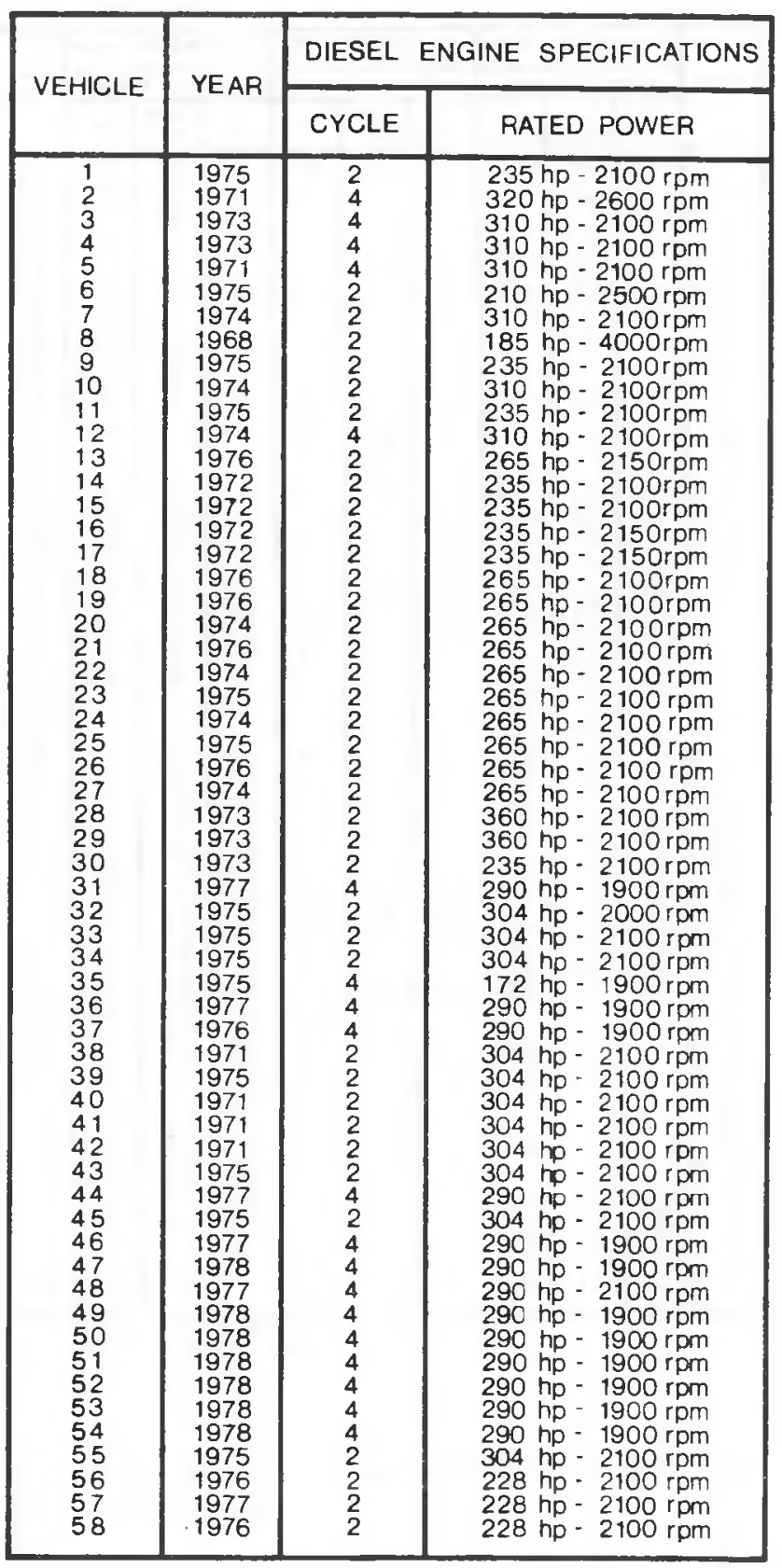

centre of cab position was noted. This appears to be predominantly due to a distinct attenuation of frequency components above $1.5 \mathrm{kHz}$. The most likely explanation of this effect is increased absorption within the cab of high frequency sound energy and shielding of wind noise.

During initial measuring runs it was observed that to be heard and be intelligible, levels of speech, radio and $C B$ radio had to be set several decibels above the environmental noise level. Typical examples are shown in Figure 2 and Figure 3 . It is interesting to note 
Table 2 - Summary of Noise Measurements

\begin{tabular}{|c|c|c|c|c|c|c|c|c|c|c|}
\hline \multirow{3}{*}{ VEHICLE } & \multicolumn{3}{|c|}{$\mathrm{L}_{\mathrm{eq}}(\mathrm{CITY})-\mathrm{dBA}$} & \multicolumn{3}{|c|}{ 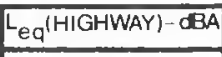 } & \multirow{2}{*}{\multicolumn{3}{|c|}{-eq(FREEWAY)-dBA }} & \multirow{3}{*}{$\begin{array}{l}\text { CSA } \\
\text { STANDARD } \\
\text { Z 107.23 }\end{array}$} \\
\hline & \multicolumn{3}{|c|}{ MICAOPHONE POSITION } & \multicolumn{3}{|c|}{ MCAOPHONF POSTITION } & & & & \\
\hline & $\begin{array}{l}\text { LEFT } \\
\text { EAR }\end{array}$ & $\begin{array}{l}\text { PIGHT } \\
\text { EAP }\end{array}$ & CAE & $\begin{array}{l}\text { LEFT } \\
\text { EAA }\end{array}$ & $\begin{array}{l}\text { RIGH } \\
\text { EAT }\end{array}$ & CAB & $\begin{array}{l}\text { LEFT } \\
\text { EAA }\end{array}$ & $\begin{array}{l}\text { RIGHT } \\
\text { EAA }\end{array}$ & $\mathrm{CAO}$ & \\
\hline 1 & $\begin{array}{l}- \\
-\end{array}$ & 85 & 83 & - & 85 & 83 & - & 89 & 90 & 81 \\
\hline$\frac{2}{3}$ & $=$ & 86 & 84 & - & - & - & $\overline{-}$ & $\begin{array}{l}90 \\
88\end{array}$ & $\begin{array}{l}91 \\
84\end{array}$ & $\begin{array}{l}85 \\
80\end{array}$ \\
\hline 4 & - & - & -4 & - & - & - & - & 87 & 87 & 88 \\
\hline $\begin{array}{l}5 \\
6\end{array}$ & $=$ & $\begin{array}{l}82 \\
86\end{array}$ & 84 & $\overline{-}$ & $\overline{-}$ & $\begin{array}{l} \\
\end{array}$ & $\overline{-}$ & $=$ & - & 83 \\
\hline 7 & $=$ & 85 & 84 & - & 85 & $=$ & - & 87 & 86 & 82 \\
\hline 9 & - & - & - & - & - & - & - & - & 87 & 81 \\
\hline $\begin{array}{l}10 \\
11\end{array}$ & - & 89 & $\overline{-}$ & $\overline{-}$ & - & $=$ & $\begin{array}{l}- \\
\end{array}$ & $\begin{array}{l}89 \\
91\end{array}$ & $\begin{array}{l}88 \\
86\end{array}$ & 86 \\
\hline & - & - & 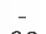 & - & - & - & - & 88 & & 85 \\
\hline $\begin{array}{l}1 \\
1.2 \\
1 .\end{array}$ & $=$ & 83 & 83 & $\overline{91} \quad$ & $\begin{array}{l}87 \\
87\end{array}$ & $\begin{array}{l}84 \\
88\end{array}$ & 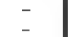 & 88 & 86 & 82 \\
\hline 15 & - & - & - & 3 & 87 & 89 & - & - & - & 84 \\
\hline 16 & - & - & $=$ & $=$ & 90 & 87 & - & $=$ & $=$ & 89 \\
\hline 18 & 83 & 81 & 80 & - & 86 & 84 & $87^{\circ}$ & 86 & 85 & 8 \\
\hline $\begin{array}{l}150 \\
20-a x-1\end{array}$ & $\begin{array}{l}90 \\
84\end{array}-10$ & $\begin{array}{l}86 \\
81\end{array}$ & $\begin{array}{l}85 \\
80\end{array}$ & 86 & 83 & 83 & $\begin{array}{l}90 \\
87^{\circ}\end{array}$ & $\begin{array}{l}87 \\
86\end{array}$ & $\begin{array}{l}86 \\
84\end{array}$ & \\
\hline & & & & & & & $91^{\circ}$ & 90 & 88 & 89 \\
\hline 22 & $\begin{array}{l}84 \\
86\end{array}$ & $\begin{array}{l}82 \\
86\end{array}$ & $\begin{array}{l}80 \\
86\end{array}$ & $\begin{array}{l}85 \\
87\end{array}$ & $\begin{array}{l}83 \\
88\end{array}$ & $\begin{array}{l}81 \\
86\end{array}$ & $\begin{array}{l}88 \\
89 .\end{array}$ & $\begin{array}{l}86 \\
90\end{array}$ & $\begin{array}{l}83 \\
86\end{array}$ & $\begin{array}{l}81 \\
87\end{array}$ \\
\hline 24 & 83 & 82 & 81 & 84 & 83 & 81 & 88 & 85 & 83 & 81 \\
\hline 25 & 84 & 83 & 81 & 86 & $\begin{array}{l}85 \\
84\end{array}$ & $\begin{array}{l}83 \\
81\end{array}$ & $87^{4}$ & $\begin{array}{l}87 \\
85\end{array}$ & 85 & 83 \\
\hline 2 & 90 & 88 & 88 & 87 & 84 & 81 & $\begin{array}{l}89 \\
92\end{array}$ & $\begin{array}{l}80 \\
90\end{array}$ & 90 & 88 \\
\hline $\begin{array}{l}28 \\
20\end{array}$ & B7 & $\begin{array}{l}89 \\
87\end{array}$ & $\begin{array}{l}88 \\
86\end{array}$ & - & - & $\overline{-}$ & $\overline{-}$ & $=$ & - & $\begin{array}{l}86 \\
88\end{array}$ \\
\hline 3 & 88 & 8 & 90 & & - & - & - & - & & 9 \\
\hline & & 8 & 87 & 92 & 90 & 88 & 96 & 90 & 90 & \\
\hline & 90 & 90 & 89 & 91 & 90 & 88 & & & 90 & 8 \\
\hline 34 & & 91 & 90 & - & 93 & 91 & $92^{\Delta 4}$ & & 91 & \\
\hline 35 & 90 & 91 & 91 & 91 & 91 & 91 & & & 90 & 93 \\
\hline 36 & 89 & 87 & 86 & - & - & - & & & $\begin{array}{l}88 \\
89\end{array}$ & \\
\hline & 92 & 88 & 87 & 91 & 90 & 89 & & & 89 & 87 \\
\hline $\begin{array}{l}39 \\
40\end{array}$ & $88^{\circ}$ & 86 & 86 & $\begin{array}{l}88^{\circ} \\
89^{*}\end{array}$ & $\begin{array}{l}89 \\
90\end{array}$ & $\begin{array}{l}86 \\
88\end{array}$ & $\begin{array}{l}88.4 \\
89.4\end{array}$ & $\begin{array}{l}90 \\
90\end{array}$ & $\begin{array}{l}85 \\
87\end{array}$ & $\begin{array}{l}87 \\
87\end{array}$ \\
\hline 4 & 89 & 88 & 86 & & - & - & & 89 & 85 & \\
\hline & 90 & 9 & 88 & $\overline{8}$ & 89 & 88 & & & 89 & $\bar{B}$ \\
\hline $\begin{array}{l}4.4 \\
4 .\end{array}$ & & - & - & & & & 8 & 88 & 87 & \\
\hline 4 & - & - & - & 92 & 91 & 90 & & & 91 & \\
\hline $\begin{array}{l}4 \\
4\end{array}$ & 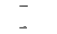 & $\begin{array}{l}84 \\
83\end{array}$ & $\begin{array}{l}83 \\
81\end{array}$ & - & 86 & 86 & $\begin{array}{l}90 \\
8 B\end{array}$ & $\begin{array}{l}88 \\
88\end{array}$ & $\begin{array}{l}88 \\
85\end{array}$ & $\begin{array}{l}84 \\
84\end{array}$ \\
\hline & - & 80 & $\because$ & . & - & - & 9 & -0 & 87 & \\
\hline 4 & - & - & - & - & $=$ & - & 92 & & 88 & \\
\hline 5 & - & - & 85 & - & - & - & - & 8 & $\begin{array}{l}80 \\
88\end{array}$ & \\
\hline & 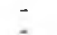 & 88 & - & - & - & - & 87 & & 86 & 84 \\
\hline 54 & 88 & - & 85 & - & - & - & $\begin{array}{l}91 \\
89\end{array}$ & 80 & 87 & 84 \\
\hline $\begin{array}{l}55 \\
56\end{array}$ & $\begin{array}{l}89 \\
85\end{array}$ & $\begin{array}{l}86 \\
88\end{array}$ & $\begin{array}{l}85 \\
84\end{array}$ & $\overline{87}$ & $\overline{8}^{-}$ & 87 & 90 & 88 & 86 & $\begin{array}{l}86 \\
85\end{array}$ \\
\hline $\begin{array}{l}57 \\
58\end{array}$ & 85 & 84 & $\begin{array}{l}91 \\
81\end{array}$ & 88 & 87 & $\begin{array}{l}92 \\
86\end{array}$ & $\begin{array}{l}- \\
-\end{array}$ & - & - & \\
\hline & & & & & & & & & & \\
\hline
\end{tabular}

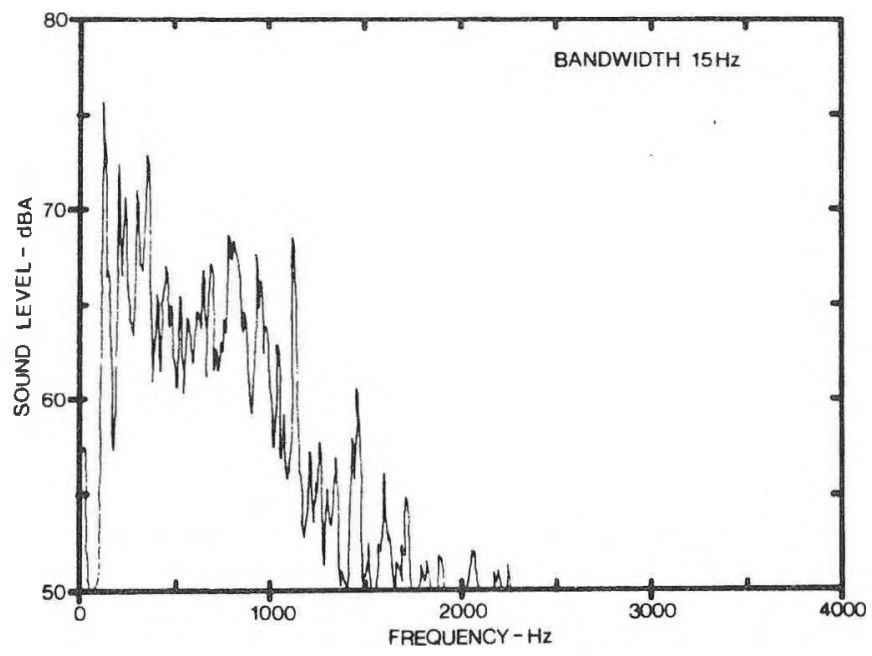

Fig. 1 - Frequency analys is of highway driving monitored at right (inner) ear that the use of a CB radio resulted in increases in instantaneous sound level of up to $10 \mathrm{~dB}$. The influence on the driver's noise exposure depends, in addition to sound levels, also upon the duration of use and location of the source. The combined effect is adequately defined by the energy equivalent level, Leq, at the reception point. Recordings were taken on several vehicles at all three measuring stations during freeway runs at a steady 100 $\mathrm{km} / \mathrm{h}$, with normal use of $C B$ radio and without it. The results are shown in Table 3. It can be seen that this effect is highest at the centre of cab position and lowest at the left ear. At the right ear an average increase in Leq of $2.7 \mathrm{~dB}$ was measured, which. will increase the Noise Exposure Rating by approximately $50 \%$.

With reference to the Lea values shown in Table 2, it can be seen that they depend upon the measuring location and their magnitudes increase in the order: CSA standard procedure, centre of cab, right ear and left ear. These increases and overall values of Leq are lowest for city driving and highest for freeway hauls. The average value of the Leq difference between freeway and city driving, measured at the right ear, is $2.9 \mathrm{~dB}$ with a standard deviation of $1.6 \mathrm{~dB}$. Although these results are not completely consistent, which appears to be primarily due to the inherent non-uniformity of the sound field in the cab, a definite trend is quite evident.

Figure 4 indicates both the variation in the Leq value for each of the three driving conditions and the corresponding sound level distributions obtained for a particular vehicle.

For freeway driving, the sound level at the left ear is on the average $5.7 \mathrm{~dB}$ higher than that measured with the CSA standard procedure. This suggests that any method of determining noise exposure which is based on measurement of sound level at some distance from the subject's ear, may results in significant underestimate. Errors in excess of $100 \%$ appear to be quite possible.

Correlations between data for the right ear, left ear and centre of cab positions, for each of the three driving conditions, were also determined. The results of two such correlations are shown in Figure 5 and Figure 6 . In these graphs, $r$ represents the correlation coefficient and o the standard deviation. Generally, the best correlation exists between the right ear and centre of cab with the value of correlation coefficient highest for city 


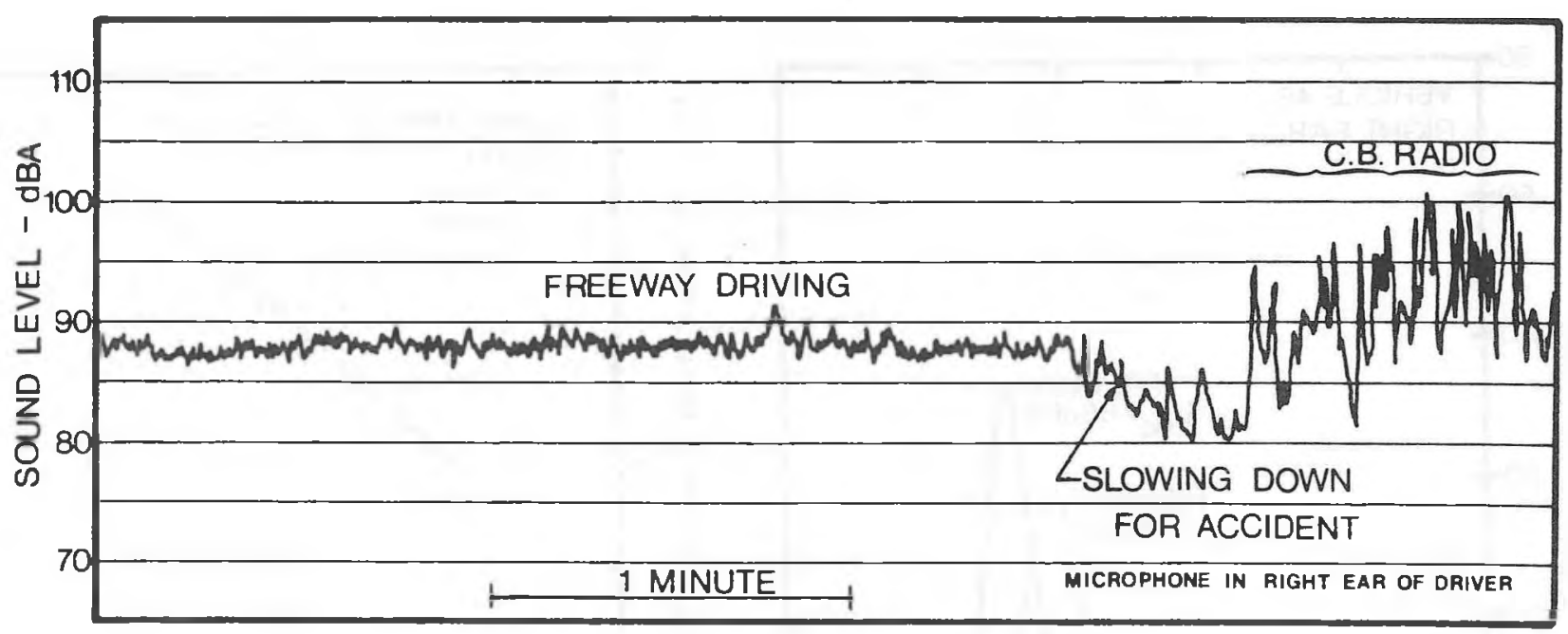

Fig. 2 - Vehicle \#53: effect of $C B$ radio on noise levels

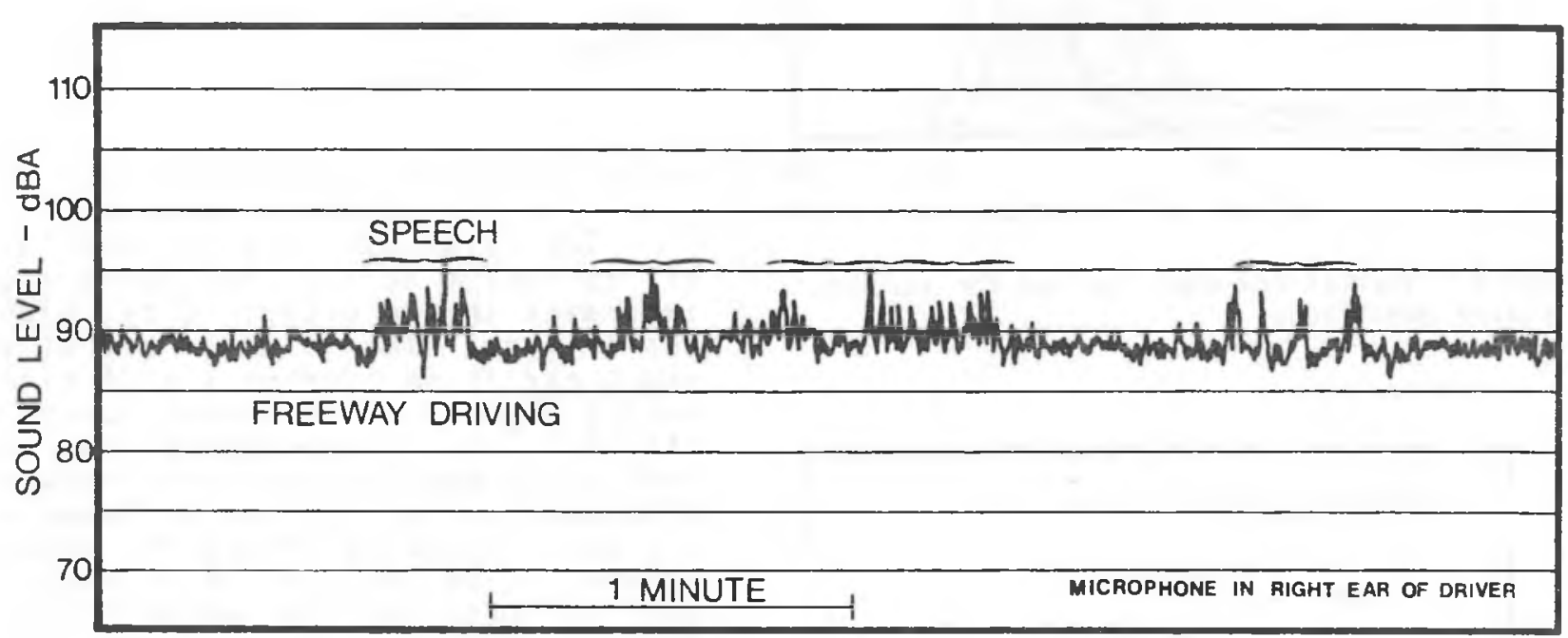

Fig. 3 - Vehicle \#48: effect of speech on noise levels

Table 3 - Effect of CB Radio on Values of $L_{e q}$

\begin{tabular}{|c|c|c|c|c|c|c|c|c|c|c|}
\hline \multirow{2}{*}{ Verecle } & \multirow{2}{*}{ 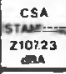 } & \multicolumn{2}{|c|}{ LEET EAR - GBA } & \multirow{2}{*}{$\begin{array}{c}\text { AELATIVE } \\
\text { EFTET } \\
\text { ARA }\end{array}$} & \multicolumn{2}{|c|}{ RXEHT EAA - DS } & \multirow{2}{*}{$\begin{array}{l}\text { PELATIVE } \\
\text { ETrET } \\
\text { maA }\end{array}$} & \multicolumn{2}{|c|}{ CEMTRF CAS - a } & \multirow{2}{*}{$\begin{array}{l}\text { AELATIVE } \\
\text { EFFECT } \\
\text { EAA }\end{array}$} \\
\hline & & no ce & WITH Ca & & wo $\mathrm{Cs}$ & For co & & wo cu & WITM CE & \\
\hline 31 & 87 & 96 & 89 & +3 & - & - & - & 90 & 95 & +5 \\
\hline 3 & 96 & 9 & & & 95 & 98 & & & 85 & +4 \\
\hline 34 & 90 & 92 & 92 & 0 & 94 & 97 & +3 & 91 & 94 & +3 \\
\hline 36 & 86 & 89 & 91 & $\cdot 2$ & 91 & 96 & .5 & 88 & 81 & +3 \\
\hline 37 & 87 & 91 & 91 & 0 & 93 & 94 & $\cdot 1$ & 89 & 92 & $\cdot 2$ \\
\hline 38 & 87 & 94 & 94 & 0 & 90 & 91 & +1 & 89 & 91 & $\cdot 3$ \\
\hline 40 & 87 & 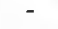 & 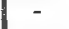 & & - & - & - & 85 & 88 & +3 \\
\hline 41 & 87 & 89 & 91 & +2 & 89 & 82 & +3 & - & - & - \\
\hline
\end{tabular}

driving and lowest for freeway driving. The results also indicate the highest noise levels exist at the left ear.

\section{CONCLUSIONS}

Under most operating conditions the sound field inside the cab is dominated by discrete frequency components. This suggests that the location of the microphone may have significant influence on measurements. For accurate determination of noise exposure the microphone should be placed within the cavum of the concha.

The use in the cab of radio or $C B$ radio can significantly increase the noise exposure of the driver. Tests performed on a sample of 8 vehicles show that normal use of $C B$ radio increases the value of Leq at the right ear by an average of $2.7 \mathrm{~dB}$. This corresponds to an increase on the noise dose of at least $50 \%$. It can thus be a significant contributor to the over- 


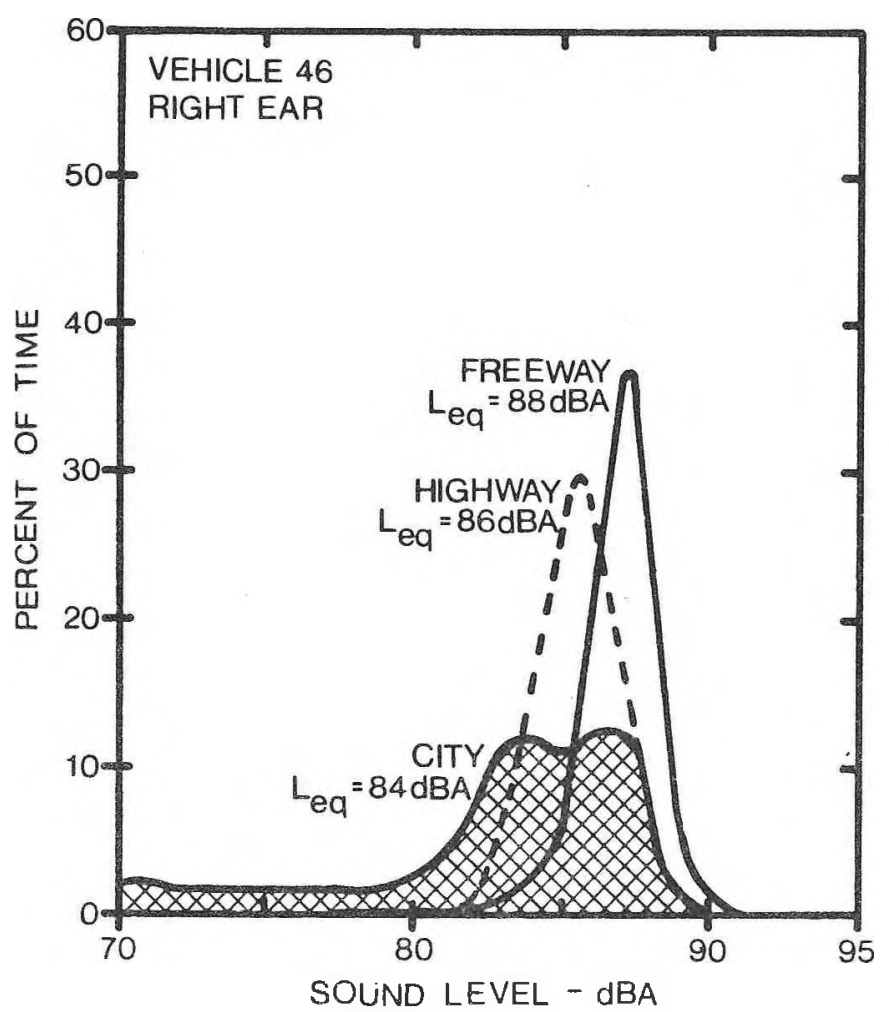

Fia. 4 - Statistical distribution for various driving conditions

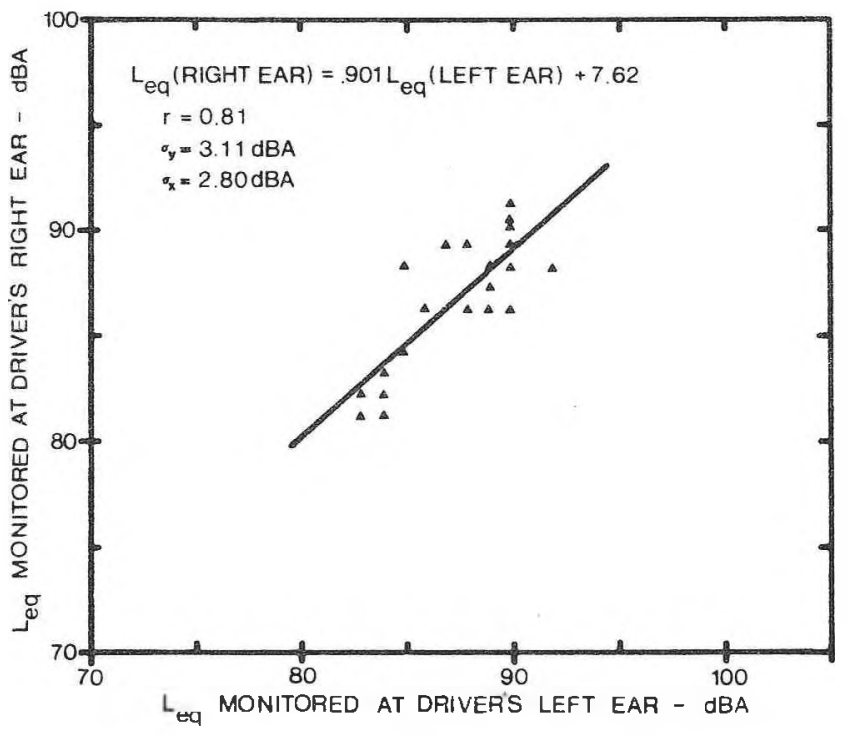

Fig. 5 - Comparison of sound levels for city driving

\section{al noise exposure.}

The sound levels measured at the centre of cab position, right and left ear of the driver, increase generally in that order. The value of the Leq at the left ear is on average $6 \mathrm{~dB}$ higher than that at the centre of cab

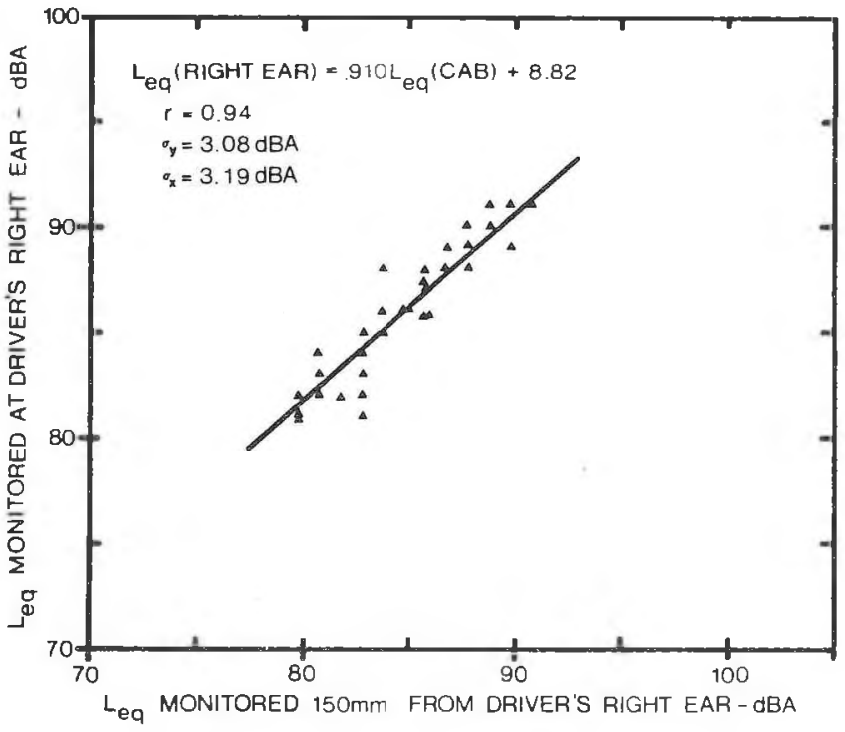

Fig. 6 - Comparison of sound levels for city driving

position, which is the measuring station used for standard procedures. The noise exposure of truck drivers is lowest during city driving and increases in the order: city, highway and freeway. The value of leq at the right ear is on average $1.5 \mathrm{~dB}$ higher during highway driving than during city driving. The corresponding comparison between highway and freeway driving shows an average difference of $1.6 \mathrm{~dB}$. The value of Leq for freeway driving is an average $2.9 \mathrm{~dB}$ higher than for city driving, which is approximately equivalent to an increase of noise exposure of $50 \%$.

\section{ACKNOWLEDGEMENT}

The support of this investigation by Road and Motor Vehicle Traffic Safety Branch, Transport Canada, Contract No. OST 77-00081 and by National Science and Engineering Research Council of Canada, Grant No. A7439 is gratefully acknowledged.

\section{REFERENCES}

1. L.S. Christensen and J.R. Hemingway, "Sources of Error in Noise Dose Measurements", B\&K Technical Review No. 3, 1973, pp. 3-13.

2. E.A.G. Shaw, "The External Ear" Handbook of Sensory Physiology, Vol. V/1; Auditory System, Springer Verlag, $1974, \mathrm{pp}$. 455-490.

3. E.A.G. Shaw, "Transformation of Sound Pressure Level from the Free Field to Ear Drum in the Horizontal Plane", JASA, Vol. 56, No. 6, 1974, 
pp. 1848-7861.

4. A.J. Brammer and J.E. Piercy, "Monitoring Sound Pressures Within the Ear: Application to Noise Exposure", JASA, Vol. 61, No. 3, 1977, pp. 731738 .

5. W.H. Close et. al, "Truck Noise II - Interior and Exterior AWeighted Sound Levels of Typical Highway Trucks, Office of the Secretary of Transportation, Washington, D.C., July 1972 .

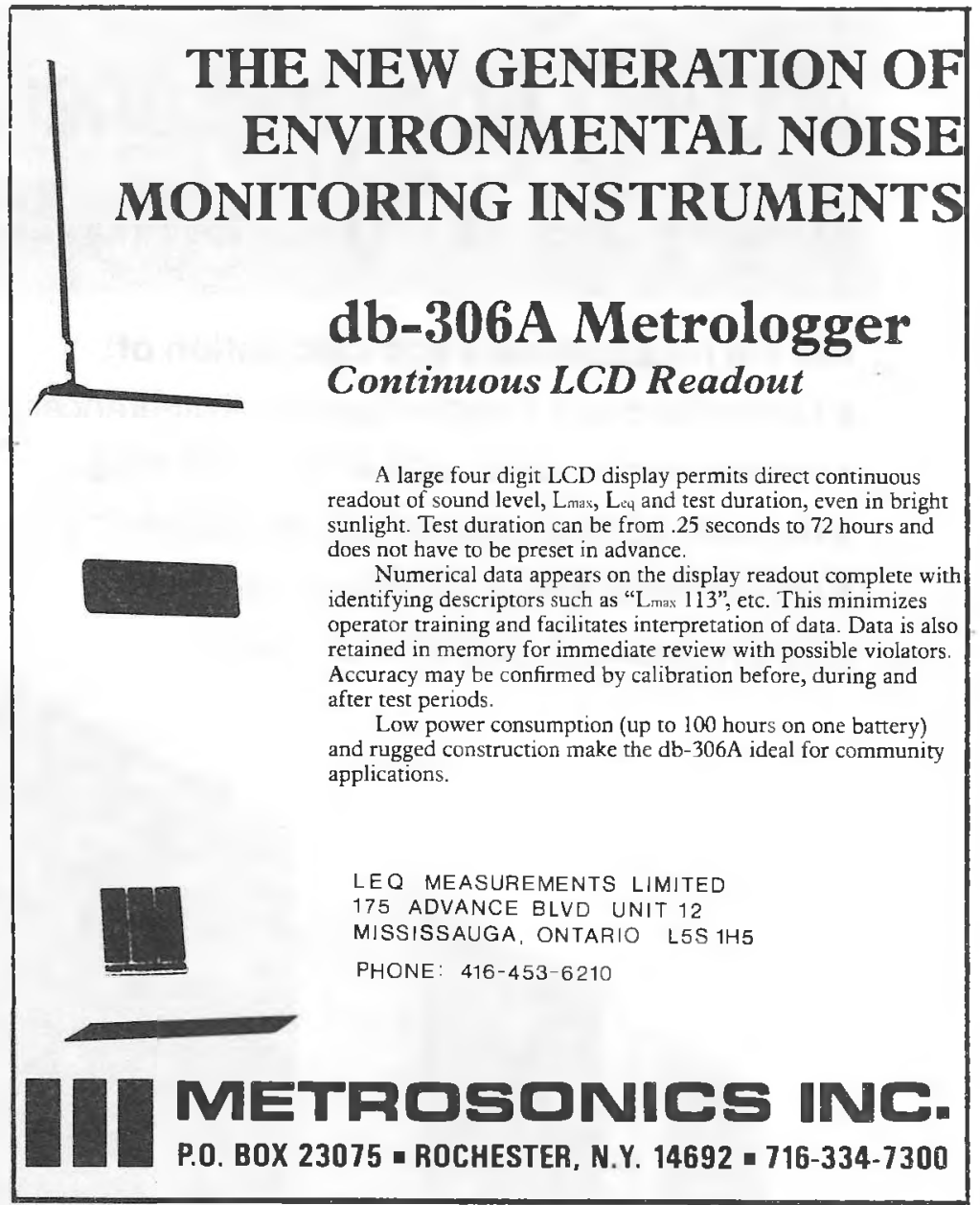

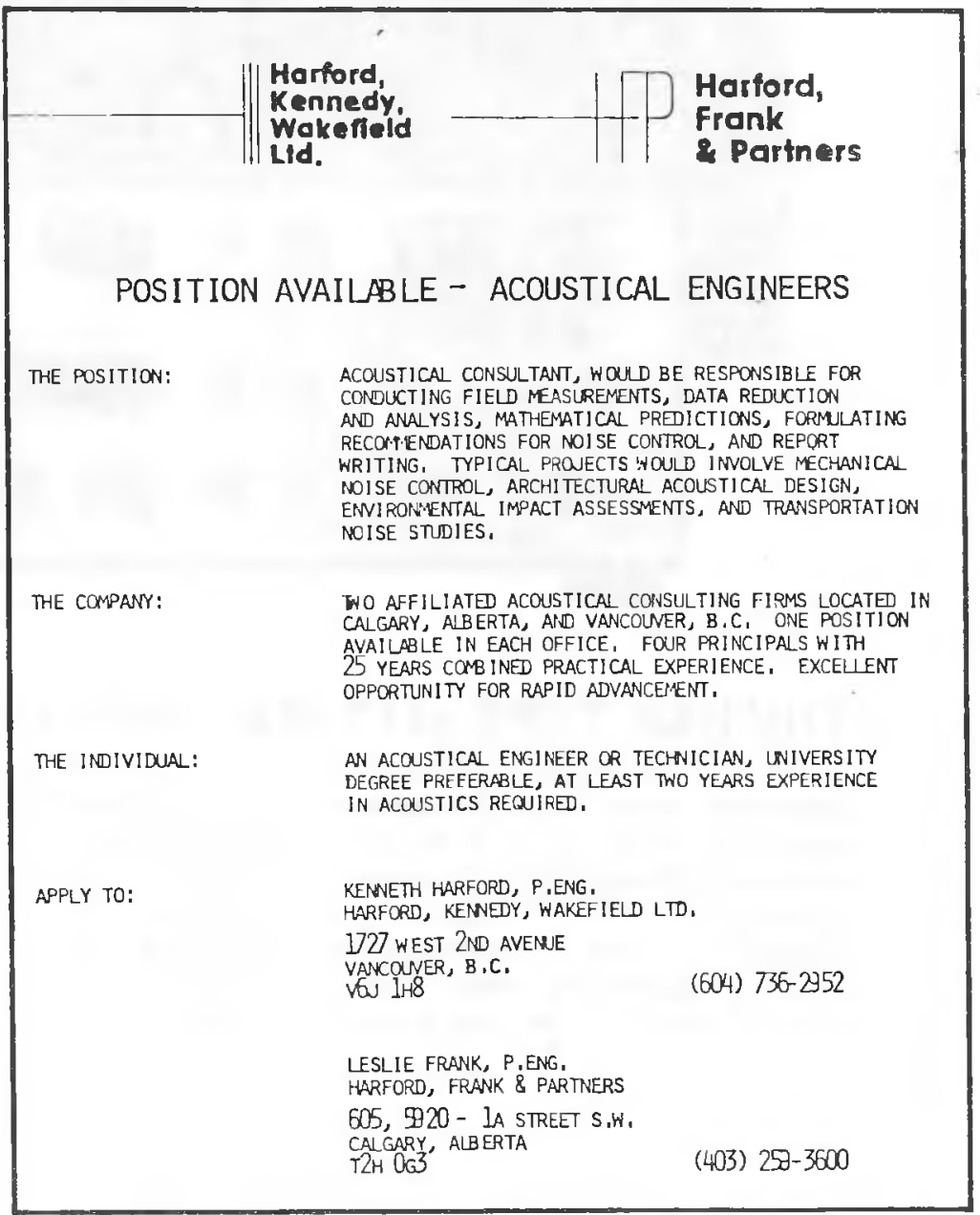




\section{NOW! Comprehensive building acoustics analysis with a single portable instrument.}

For the measurement and calculation of:

- Normalised and standardised level differences (ISO 140)

- Reverberation times (ISO R 354, ISO 3382)

- Airborne noise insulation indices (ISO R 717)

- Impact noise insulation indices (ISO R 717)

- Sound power (ISO 3741 and 3742)

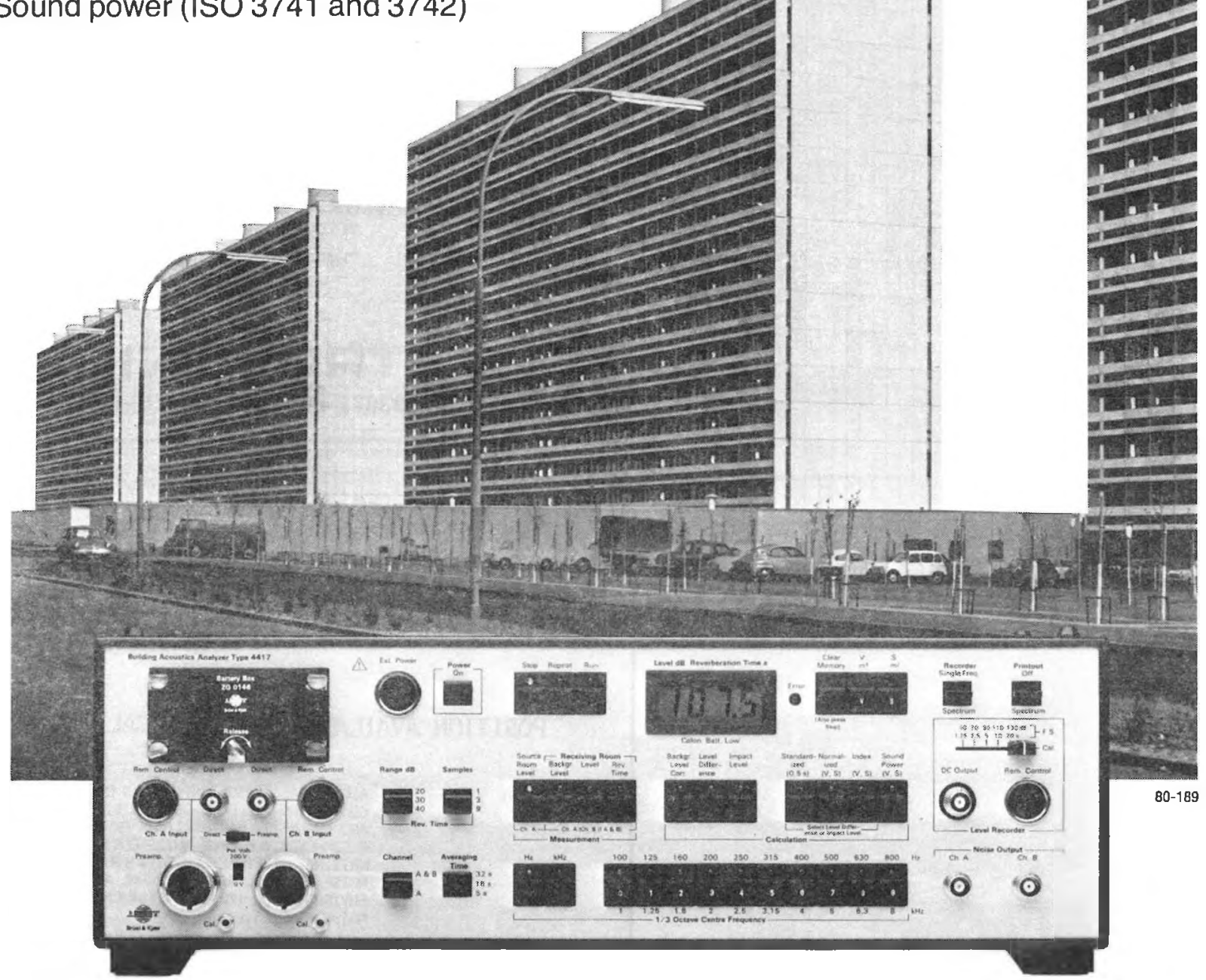

\section{THE B\&K TYPE 4417 BUILDING ACOUSTICS ANALYSER}

combines every required building acoustics measurement capability in a single compact, portable instrument. In addition to the specific data noted in the illustration, the 4417 evaluates noise reduction; investigates sound field distribution; determines loss factors of building elements. It runs on its own internal power supply; requires only a microphone and speak- er system for operation. Of special interest is a system of measurement and calculation error codes, with the pertinent code number displayed on the face of the instrument for prompt identification and correction. For more detailed information, or to arrange a demonstration, call any Bruel \& Kjaer office. 


\section{PLUS instantaneous data storage, retrievable at the touch of a button.}

- IEC/IEEE and B\&K Low Power interface compatibility

- Fast retrieval of data -4 digit data location display
- Complete manual or remote control

- Mains or DC powered for maximum versatility

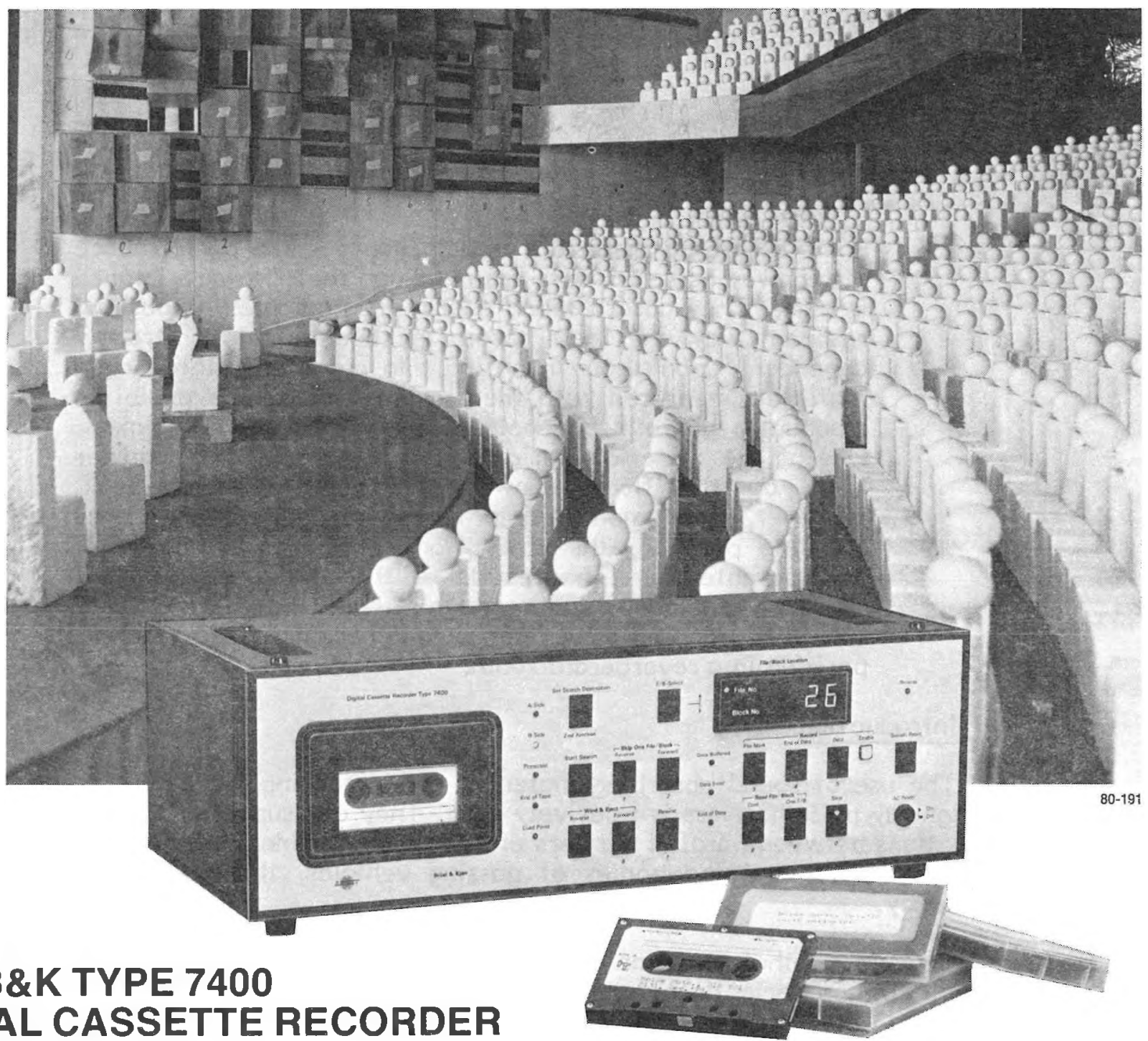

THE B\&K TYPE 7400 DIGITAL CASSETTE RECORDER

is the ideal complement to the Building Acoustics Analyser. Results are stored as they happen, - up to $500 \mathrm{~K}$ bytes of data on a single cassette - and are instantly retrievable by touching a button. The Type 7400 is, in fact, the most efficient data storage and retrieval instrument you could have in your lab, because it is compatible with all B\&K (and most other) instruments. Write or phone for more information, or a no-obligation demonstration.

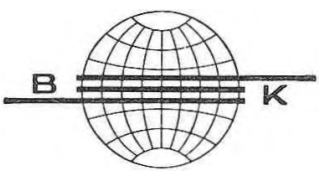

BRUEL \& KJAER CANADA LTD.

\section{Specialists in acoustic and vibration measurement}

MONTREAL

90 Leacock Road

Pointe Claire, Que. $\mathrm{H} 9 \mathrm{H} \quad 1 \mathrm{H} 1$

Tel.: (514) 695-8225
OTTAWA

7 Slack Road, Suite 201

Ottawa, Ont. K2G OB?

Tel.: (613) 225-7648
TORONTO

71 Bramalea Road, Suite 71D

Bramalea, Ont. L6T 2W9 Tel.: (416) 791-1642

\section{LONDON}

23 Chalet Crescent

London, Ont. N6K 3C5

Tel.: (519) 473-3561
VANCOUVER

5520 Minoru Boulevard, Room 202

Richmond, B.C. V $6 \times 2 \mathrm{~A} 9$

Tel.: (604) 278-4257 